\title{
EDUCAÇão INCLUSIVA, OS DESAFIOS PARA SUA EFETIVAÇÃo
}

\author{
INCLUSIVE EDUCATION, THE CHALLENGES FOR THEIR
}

\author{
EFFECTIVENESS
}

\author{
Carla Campos de Oliveira Almeida \\ Mestra em Educação pela Universidade Nove de Julho. Orientadora Pedagógica da \\ Educação Especial da Prefeitura Municipal de Extrema. Extrema - MG - Brasil \\ kalukampos@bol.com.br
}

\begin{abstract}
Resumo: As políticas públicas educacionais no Brasil vêm se modificando ao longo das últimas décadas, na busca de assegurar cada vez mais os direitos das pessoas com deficiência, isto é, dos alunos com necessidades educacionais especiais (NEE). Nesta trajetória de grandes conquistas, principalmente referente às legislações, nos deparamos cada vez mais com os desafios das implementações previstas nas mesmas, sejam elas, a formação docente, adaptação curricular, espaços escolares adaptados etc. Neste sentido, o presente artigo propõe uma leitura do que é proposto na teoria e o que realmente acontece na prática e no dia a dia escolar, seus pontos e contrapontos. Pois, visa à reflexão de possíveis caminhos para a efetivação de uma educação verdadeiramente inclusiva.

Palavras-chave: Educação inclusiva. Desafios. Legislações. Alunos com necessidades educacionais especiais (NEE).

Abstract : Public educational policies in Brazil have been changing over the last decades, in the search to ensure more and more the rights of people with disabilities, that is, of students with special educational needs (SEN). In this trajectory of great achievements, mainly referring to the legislations, we are increasingly faced with the challenges of the implementations envisaged in them, be they teacher training, curricular adaptation, adapted school spaces, etc. In this sense, the present article proposes a reading of what is proposed in theory and what really happens in practice and in the day to day school, its points and counterpoints. For, it aims at the reflection of possible ways for the realization of a truly inclusive education.
\end{abstract}

Cadernos de Pós-graduação, São Paulo, v. 17, n. 2, p. 239-249, jul./dez. 2018. 
Key-words: Inclusive education. Challenges. Legislation. Students with special educational needs (SEN).

\section{Introdução}

s políticas públicas ao longo dos últimos anos têm cada vez mais enfati-
zado os direitos da pessoa com deficiência, principalmente no âmbito da educação.

A escola inclusiva brasileira tem sólidas fundações, na lei, no vanguardismo dos que se dispuseram expandi-la, verdadeiramente imbuídos do compromisso de transformá-la, para se adequar ao nosso tempo. Eles estão se multiplicando e surpreendendo, demonstrando a força desta ideia poderosa - que depende de uma expansão rápida dos projetos verdadeiramente imbuídos do compromisso de transformar a escola comum para se adequar aos novos tempos (MANTOAN, 2015, p. 36).

A ideia de uma educação efetivamente inclusiva impulsionou, nas últimas décadas, significativas mudanças na educação e orientou a transformação nos sistemas de ensino no Brasil.

As mudanças ocorridas nos sistemas de ensino brasileiro em prol de uma educação inclusiva precedem da somatória de esforços que resultaram em grandes conquistas. Tais conquistas se materializaram ao longo de décadas em formas de leis, decretos, portarias e resoluções, que embasam a Política de Educação Inclusiva no Brasil. Para melhor elucidar parte desta trajetória histórica e das mudanças ocorridas, até a chegada da proposta de consolidação de educação na perspectiva inclusiva, analisemos a tabela a seguir: 


\begin{tabular}{|c|c|}
\hline Ano & Lei \\
\hline 1961 & Lei de Diretrizes e Bases da Educação Nacional - Lei no 4.024/61 \\
\hline 1971 & Lei de Diretrizes e Bases da Educação Nacional - Lei no 5.692/71 \\
\hline 1988 & Constituição da República Federativa do Brasil de 1988. \\
\hline 1989 & Lei $n^{\circ} 7.853 / 89$. \\
\hline 1990 & Estatuto da Criança e do Adolescente - Lei no. 8.069/90. \\
\hline 1990 & Declaração Mundial de Educação para Todos. \\
\hline 1994 & Declaração de Salamanca. \\
\hline 1996 & Lei de Diretrizes e Bases da Educação Nacional - Lei no 9.394/96. \\
\hline 1999 & Decreto $\mathrm{n}^{\circ} 3.298$ que regulamenta a Lei $\mathrm{n}^{\circ} 7.853 / 89$. \\
\hline 2001 & $\begin{array}{l}\text { Diretrizes Nacionais para a Educação Especial na Educação Básica (Resolução CNE/CEB no } \\
\qquad 2 / 2001) .\end{array}$ \\
\hline 2001 & Plano Nacional de Educação - PNE, Lei no 10.172/2001. \\
\hline 2001 & Convenção da Guatemala (1999), promulgada no Brasil pelo Decreto no 3.956/2001. \\
\hline 2002 & Resolução CNE/CP n¹/2002. \\
\hline 2002 & Lei n ${ }^{\circ} 10.436 / 02$. \\
\hline 2004 & Decreto $n^{\circ} 5.296 / 04$ \\
\hline 2005 & Decreto $\mathrm{n}^{\circ} 5.626 / 05$. \\
\hline 2006 & Plano Nacional de Educação em Direitos Humanos. \\
\hline 2007 & Plano de Desenvolvimento da Educação - PDE. \\
\hline 2007 & Decreto $n^{\circ} 6.094 / 07$ \\
\hline 2008 & Política Nacional de Educação Especial na Perspectiva da Educação Inclusiva. \\
\hline 2008 & Decreto $\mathrm{n}^{\circ} 6.571$. \\
\hline 2009 & Convenção sobre os Direitos das Pessoas com Deficiência. \\
\hline 2009 & Decreto $\mathrm{n}^{\circ} 6.949$. \\
\hline 2009 & Resolução No. 4 CNE/CEB. \\
\hline 2011 & Plano Nacional de Educação (PNE - 2011 - 2020) - Projeto de Lei. \\
\hline 2012 & Lei $\mathrm{n}^{\circ} 12.764$. \\
\hline 2014 & LEI N ${ }^{\circ} 13.005$, DE 25 DE JUNHO DE 2014. \\
\hline 2015 & $\begin{array}{l}\text { Lei n }{ }^{\circ} \text { 13.416/2015, que institui a Lei Brasileira de Inclusão da Pessoa com Deficiência, conhecida } \\
\text { como Estatuto da Pessoa com Deficiência. }\end{array}$ \\
\hline 2016 & A Consolidação Escolar da Inclusão no Brasil 2003 a 2016. \\
\hline
\end{tabular}

Fonte: elaborada pela autora (2017). 
Dentre as inúmeras legislações citadas e organizadas cronologicamente na tabela anterior que amparam a pessoa com deficiência no âmbito educacional, foram elencadas algumas, para fundamentar o presente artigo.

Em 1961, o atendimento educacional às pessoas com deficiência passa a ser fundamentado pelas disposições da Lei de Diretrizes e Bases da Educação Nacional Lei n ${ }^{\circ}$ 4.024/61, que aponta o direito dos “excepcionais” à educação, preferencialmente dentro do sistema geral de ensino.

A Lei $\mathrm{n}^{\circ}$ 5.692/71, que altera a LDBEN de 1961, ao definir "tratamento especial” para os estudantes com "deficiências físicas, mentais, os que se encontram em atraso considerável quanto à idade regular de matrícula e os superdotados", não promove a organização de um sistema de ensino capaz de atender aos estudantes com deficiência, transtornos globais do desenvolvimento e altas habilidades/superdotação e acaba reforçando o encaminhamento dos estudantes para as classes e escolas especiais.

Em 1973, o MEC cria o Centro Nacional de Educação Especial (CENESP), responsável pela gerência da educação especial no Brasil, que, sob a égide integracionista, impulsionou ações educacionais voltadas às pessoas com deficiência e às pessoas com superdotação, mas ainda configuradas por campanhas assistenciais e iniciativas isoladas do Estado.

Nesse período, não se efetiva uma política pública de acesso universal à educação, permanecendo a concepção de "políticas especiais" para tratar da educação de estudantes com deficiência. No que se refere aos estudantes com superdotação, apesar do acesso ao ensino regular, não é organizado um atendimento especializado que considere as suas singularidades de aprendizagem.

A Constituição Federal de 1988 traz como um dos seus objetivos fundamentais "promover o bem de todos, sem preconceitos de origem, raça, sexo, cor, idade e 
quaisquer outras formas de discriminação" (artigo $3^{\circ}$, inciso IV). Define, no artigo 205, a educação como um direito de todos, garantindo o pleno desenvolvimento da pessoa, o exercício da cidadania e a qualificação para o trabalho. No seu artigo 206, inciso I, estabelece a "igualdade de condições de acesso e permanência na escola" como um dos princípios para o ensino e garante como dever do Estado, a oferta do atendimento educacional especializado, preferencialmente na rede regular de ensino (artigo 208).

A Conferência Mundial de Educação para Todos, Jomtien/1990, chama a atenção para os altos índices de crianças, adolescentes e jovens sem escolarização, tendo como objetivo promover transformações nos sistemas de ensino para assegurar o acesso e a permanência de todos na escola.

Para o alcance das metas de educação para todos, a Conferência Mundial de Necessidades Educativas Especiais: Acesso e Qualidade, realizada pela UNESCO em 1994, propõe aprofundar a discussão, problematizando as causas da exclusão escolar. A partir desta reflexão acerca das práticas educacionais que resultam na desigualdade social de diversos grupos, o documento Declaração de Salamanca e Linha de Ação sobre Necessidades Educativas Especiais proclama que as escolas comuns representam o meio mais eficaz para combater as atitudes discriminatórias, e que estudantes com deficiência, transtornos e altas habilidades/superdotação devem ter acesso à escola regular, tendo como princípio orientador que "as escolas deveriam acomodar todas as crianças independentemente de suas condições físicas, intelectuais, sociais, emocionais, linguísticas ou outras” (BRASIL, 2007).

Considerando que a educação constitui-se em direito humano fundamental, incondicional e indisponível, assegurado no ordenamento jurídico brasileiro e sua efetivação deve ser cumprida sem distinção, em todos os níveis, etapas e modalidades de ensino, cumpre destacar que a Lei no 13.416/2015, que institui a Lei Brasileira de In- 
clusão da Pessoa com Deficiência, conhecida como Estatuto da Pessoa com Deficiência, sistematizou dispositivos relativos ao direito das pessoas com deficiência à educação, constantes da Convenção sobre os Direitos das Pessoas com Deficiência - CDPD, do Estatuto da Criança e do Adolescente - ECA e da Lei $n^{\circ}$ 13005/2014, que institui o Plano Nacional de Educação (PNE), assim como, especificou medidas contidas em Decretos Federais, Notas Técnicas emitidas pelo Ministério da Educação e em Resoluções publicadas pelo Conselho Nacional de Educação, que fazem parte do processo de implementação da Política Nacional de Educação Especial na Perspectiva da Educação Inclusiva, elaborada à luz do artigo 24 da Convenção sobre os Direitos das Pessoas com Deficiência - ONU/2006.

Neste sentido, a atual Política Nacional de Educação Especial na Perspectiva da Educação Inclusiva tem como objetivo o acesso, a participação e a aprendizagem dos estudantes com deficiência, transtornos globais do desenvolvimento e altas habilidades/superdotação nas escolas comuns.

No entanto, mesmo com uma perspectiva conceitual que aponte para a organização de sistemas educacionais inclusivos, que garanta o acesso de todos os estudantes e os apoios necessários para sua participação e aprendizagem, as políticas implementadas pelos sistemas de ensino, num contexto geral, ainda não alcançaram esse objetivo. Pois, segundo a orientação do PNE (2014) aos sistemas de ensino, para promover respostas às necessidades educacionais, deve ser garantido ao estudante com NEE:

a) Transversalidade da educação especial desde a educação infantil até a educação superior.

Subentende-se como um possível caminho de promover a transversalidade da educação especial seja a adaptação curricular, para os alunos com NEE, isto é, o Plano de Desenvolvimento Individual do Aluno (PDI), previsto no artigo 59 da Lei de Diretrizes e Bases da Educação Nacional (LDBEN, Lei no 9.394/96), "preconiza que os 
sistemas de ensino devem assegurar aos alunos currículo, métodos, recursos e organização específicos para atender às suas necessidades”. E está também, assegurado no art. $7^{\circ}$ da resolução das normas sobre a Educação Especial na Educação Básica, no Sistema Estadual de Ensino de Minas Gerais:

Art. $7^{\circ}$ - Compete às instituições de ensino para oferta da educação especial: identificar e elaborar recursos pedagógicos, produzir e organizar serviços de acessibilidade e estratégias considerando as necessidades específicas dos alunos; elaborar e aplicar o PDI, visando avaliar as condições e necessidades dos alunos (MINAS GERAIS, 2013).

O PDI é um instrumental que viabiliza e norteia o trabalho docente, pois oportuniza o professor a pensar e a registrar os conteúdos e estratégias a serem trabalhados com os alunos com necessidade educacional especial (NEE), e assim acompanhar os possíveis avanços dos alunos, além de possibilitar a reflexão sobre sua prática docente.

Mesmo previsto há mais de 21 anos no artigo 59 da LDB, o PDI continua a ser um instrumental teórico, pouco conhecido na prática docente e consequentemente não assegurando os direitos dos alunos com NEE.

b) Atendimento educacional especializado (AEE);

De acordo com a resolução do CNE (2009) no artigo 5º AEE é realizado prioritariamente na sala de recursos multifuncionais da própria escola ou de outra escola, no turno inverso da escolarização, não sendo substitutivo às classes comuns. A elaboração e execução do Plano de AEE são de competência dos professores que atuam nas salas de recursos multifuncionais em articulação com os demais professores do ensino comum, com a participação da família e em interface com os demais serviços setoriais.

c) Continuidade da escolarização nos níveis mais elevados do ensino; 
A “educação é direito inalienável de todos os seres humanos sem distinção de qualquer natureza", bem como a educação inclusiva respaldado por novos marcos legais, políticos e pedagógicos, visam assegurar cada vez mais o direito a escolarização formal nas turmas comuns no ensino regular, isto é, da educação infantil ao ensino superior. De modo a ofertar aos alunos com NEE o apoio necessário que maximize o seu desenvolvimento acadêmico, seja através de um profissional de apoio que o auxilie e/ou através de adaptações curriculares segundo suas necessidades. A finalidade da educação inclusiva é superar o modelo de deficiência visto por muito tempo como invalidez, e promover uma educação pautada no respeito, na identidade e na autonomia, cuja intencionalidade é assegurar a igualdade de oportunidades.

d) Formação de professores para o atendimento educacional especializado, demais profissionais da educação para a inclusão escolar;

O professor, antes de ingressar na ação efetiva da docência, não imagina os inúmeros desafios que fazem parte do ofício de ensinar/educar. Ao iniciar seu trabalho nas escolas, o medo do novo, a insegurança por não saber o que fazer, acaba levando os professores a direcionarem seu trabalho para alunos que melhor possam responder ao seu ensino e apresentar melhores desempenhos nas aprendizagens. Essa questão ainda está presente nas salas de aula atualmente, pois é mais fácil investir onde se vê retorno. Esta maneira de pensar e de sentir, afeta de maneira ainda mais séria, os docentes que se destinam, ou são destinados ao trabalho com alunos com necessidades educacionais especiais (NEE).

Para tanto, um possível caminho para se avaliar alunos com NEE deve partir da premissa e da clareza por parte do professor de que somos indivíduos únicos e singulares, por esse motivo não deve haver intenção de comparação entre os alunos, mas a elaboração e a aplicação da avaliação devem basear-se no potencial e respeito. Por esse motivo é necessário que o professor tenha constituído vínculo com o aluno, tenha 
trabalhado de maneira flexibilizada, as estratégias e conteúdos, se necessário, de modo á respeitar o tempo e ritmo do mesmo.

Alunos que apresentam dificuldades de aprendizagens e, principalmente alunos laudados como tendo alguma deficiência, considerados com NEE, são vistos como incógnitas. Geralmente sabe-se o diagnóstico, mas o prognóstico é imprevisível, pois não há receitas, embora haja muitas informações referentes às características da deficiência e possíveis comprometimentos cognitivos, não há certezas sobre possíveis avanços nas aprendizagens. O tema da inclusão está em evidência, nesse momento, mas, muitas ações dão a impressão que estamos vivendo a exclusão.

e) Participação da família e da comunidade;

A família é peça fundamental no processo ensino/aprendizagem do aluno com NEE, além de ter o direito e o dever de acompanhar a vida acadêmica de seu filho, sendo assim, devem ser participados e estar cientes e envolvidos em todo trabalho, a ser, e desenvolvido na escola, e comunidade escolar.

f) Acessibilidade urbanística, arquitetônica, nos mobiliários e equipamentos, nos transportes, na comunicação e informação;

Pauta-se no direito de ir e vir com segurança e autonomia de acordo com o disposto no Decreto n ${ }^{\circ}$ 5.296/2004, como também no artigo 9 da Convenção sobre os Direitos das Pessoas com Deficiência, independentemente da matrícula de estudantes com deficiência na instituição de ensino.

g) Articulação intersetorial na implementação das políticas públicas;

Sendo um possível caminho de viabilizar, assegurar os direitos e auxiliar a pessoa com deficiência, principalmente a classe menos favorecida, não somente na educação, como também na saúde, moradia, trabalho, esporte e lazer, condições básicas e essenciais para que a mesma possa gozar de uma vida digna e plena. 


\section{Considerações Finais}

Por muito tempo perdurou o entendimento de que a educação especial, organizada de forma paralela à educação comum, seria a forma mais apropriada para o atendimento de alunos que apresentavam deficiência, transtornos, superdotação/altas habilidades, alunos com necessidade educacional especial (NEE), e que não se adequassem à estrutura rígida dos sistemas de ensino. Esta concepção foi mudando ao longo dos anos. De acordo com a evolução dos modelos de interpretação da deficiência, é cada vez mais exigido que seja assegurado às pessoas com deficiência o direito à educação em ambientes escolares inclusivos.

Após mais de duas décadas continuamos a engatinhar na compreensão das mudanças referentes aos entendimentos e práticas relacionadas à educação desses alunos. Ocorreram, por certo avanços, mas são muito pequenos diante das necessidades de muitas mudanças que os estudos recentes indicam.

É fato que a formação do professor interfere no ensino e no processo de aprendizagens dos alunos, positiva ou negativamente, e que a avaliação serve como instrumento dinâmico e termômetro referente às práticas pedagógicas.

Então, o que me parece, é que quando estamos abertos a acolher e a respeitar as diferenças, damos um primeiro passo. $\mathrm{O}$ passo seguinte acontece, quando na percepção da singularidade do aluno com necessidade educacional especial (NEE) o foco não se faz na deficiência e sim no seu potencial.

Contudo, os sistemas de ensino devem organizar as condições de acesso aos espaços, aos recursos pedagógicos e à comunicação que favoreçam a promoção da aprendizagem e a valorização das diferenças, de forma a atender as necessidades educacionais de todos os estudantes. 


\section{Referências}

BRASIL. Ministério da Educação. Comitê Nacional de Educação em Direitos Humanos. Plano Nacional de Educação em Direitos Humanos. Brasília: Secretaria Especial dos Direitos Humanos, Ministério da Educação, Ministério da Justiça, UNESCO, 2007.

MANTOAN, Maria Teresa Eglér. O que é? Por quê? Como fazer? São Paulo, SP: Summus Editorial, 2015.

MINAS GERAIS. Conselho Estadual de Educação. Resolução n 460, de 12 de dezembro de 2013. Consolida normas sobre a Educação Especial na Educação Básica no Sistema Estadual de Ensino de Minas Gerais e dá outras providências. Belo Horizonte, 2013.

recebido em 20 ago. 2017 / aprovado em 17 set. 2018

Para referenciar este texto:

ALMEIDA, C. C. O. Educação inclusiva, os desafios para sua efetivação. Cadernos de Pós-graduação, São Paulo, v. 17, n.2, p. 239-249, jul./dez. 2018. Disponível em: $<$ https://doi.org/10.5585/cpg.v17n2.7716>. 